\title{
EDUCAÇÃO INDÍGENA E SEUS MODOS DE PRODUÇÃO DE CONHECIMENTO: UM ESTUDO SOBRE A PRODUÇÃO DA CERÂMICA ENTRE FAMÍLIAS KIRIRI, EM JACOBINA/BA
}
INDIGENOUS EDUCATION AND ITS TYPES OF PRODUCTION OF KNOWLEDGE: A STUDY ABOUT THE PRODUCTIONS OF CERAMICS AMONG KIRIRI FAMILIES, IN JACOBINA / BA

\section{EDUCACIÓN INDÍGENA E SUS MODOS DE PRODUCCIÓN DE CONOCIMIENTO: UN ESTUDIO SOBRE LA PRODUCCIÓN DE CERÁMICA ENTRE FAMILIAS KIRIRI, EN JACOBINA/BA}

\author{
José Valdir Jesus de Santana ${ }^{1}$ \\ Camila Silva de Oliveira ${ }^{2}$ \\ Danilo César Souza Pinto ${ }^{3}$
}

\begin{abstract}
Resumo: Nesta pesquisa, nosso objetivo foi identificar e analisar os modos de produção e transmissão de conhecimento e, portanto, das "experiências de aprendizagem" que indígenas Kiriri, localizados no município de Jacobina/BA, acionam no sentido de se produzirem enquanto coletivo; compreender os sentidos de educação e aprendizagem e do que é importante aprender tendo como foco central a produção da "cerâmica Kiriri", posto que é a partir dela que os Kiriri atualizam relações com parentes que permaneceram na Terra Indígena em Banzaê/BA e com regimes de conhecimento que seriam próprios desse povo. As narrativas apresentadas pelo grupo e as etnografias sobre os Kiriri estão marcadas pela confluência da produção de cerâmica que marcam aspectos da educação deste povo e suas múltiplas formas de produção de cultura e etnicidade.
\end{abstract}

Palavras-chave: Educação indígena. Cerâmica Kiriri. Produção de conhecimento.

\begin{abstract}
In this research, our goal was to identify and analyze the types of production and transmission of knowledge and, therefore, the "learning experiences" that Kiriri indigenous people, located in Jacobina / BA, act in the sense of produce as a collective; to understand the meaning of education and learning and what is important to learn with the central focus on the production of "Kiriri ceramic", in view that it is from it that the Kiriri update relations with relatives who remained in the Indigenous Land in Banzaê / BA and with knowledge regimes that would be proper to that people. The narratives presented by the group and the ethnographies about the Kiriri are characterized by the confluence of the production of ceramics that mark aspects of the education of these people and their multiple ways of producing culture and ethnicity.
\end{abstract}

\footnotetext{
${ }^{1}$ Universidade Estadual do Sudoeste da Bahia. Vitória da Conquista, Bahia, Brasil.

${ }^{2}$ Prefeitura Municipal de Coração de Maria. Coração de Maria, Bahia, Brasil.

${ }^{3}$ Universidade Estadual do Sudoeste da Bahia. Jequié, Bahia, Brasil.
} 
Keywords: Indigenous education. Kiriri ceramics. Knowledge production.

Resumen: En esta investigación, nuestro objetivo fue identificar y analizar los modos de producción y transmisión y conocimiento y, por lo tanto, de las "experiencias de aprendizaje" que indígenas Kiriri, localizados en el condado de Jacobina/BA, desencadenan en el sentido de producirse mientras colectivo; comprender los sentidos de educación y aprendizaje y de lo que es importante aprender teniendo atención central la producción de la "cerámica Kiriri", puesto que es a partir de ella que los Kiriri actualizan relaciones con parientes que se quedaron en la Tierra indígena en Banzaê/BA y con regímenes de conocimiento que serían propios de ese pueblo. Las narrativas presentadas por el equipo y las etnografías sobre os Kiriri están marcadas por la confluencia de la producción de cerámica que señalan aspectos de educación de ese pueblo y sus múltiples formas de producción de cultura y etnicidad.

Palabras clave: Educación indígena. Cerámica Kiriri. Producción de conocimiento.

\section{INTRODUÇÃO}

Este artigo constitui-se em um recorte da pesquisa de mestrado (OLIVEIRA, 2019) realizada no Programa de Pós-Graduação em Relações Étnicas e Contemporaneidade da Universidade Estadual do Sudoeste da Bahia. O objetivo da pesquisa foi identificar e analisar os modos de produção e transmissão de conhecimento e, portanto, das "experiências de aprendizagem" e compreender os sentidos de educação e aprendizagem e do que é importante aprender, que indígenas Kiriri, localizados no município de Jacobina/BA, acionam para se produzirem enquanto coletivo, tendo como foco central a produção da "cerâmica Kiriri".

O encontro com a produção acadêmica sobre os Kiriri e a etnografia (PEIRANO, 2014) por nós realizada foram centrais para o entendimento da relação entre produção de conhecimento, etnicidade e a história da atual existência deste grupo em Jacobina. Buscamos, então, propiciar o diálogo dos relatos deste grupo Kiriri com alguns registros/reflexões produzidos por etnografias realizadas junto a esse povo, na medida em que nos permitiu a compreensão da trajetória e da construção deste coletivo.

As narrativas apresentadas pelo grupo e as etnografias sobre os Kiriri estão marcadas pela confluência da produção de cerâmica que marcam aspectos da educação deste povo e suas múltiplas formas de produção de cultura e etnicidade. O texto aqui privilegia a história a partir da experiência dos indígenas, por considerar o seu protagonismo nas situações de contato. A posição teórico-metodológica assumida se coloca junto à percepção de que os sujeitos da pesquisa são produção e produtores das discursividades que reconfiguram os sujeitos das culturas em sua própria movimentação, que evidenciam suas negociações e escolhas. 
Nesse sentido, enquanto pesquisadores, somos também produções das discursividades, e a maior precisão do objeto, a configuração do campo, a experimentação de pesquisa são produtos desta relação de forças, de modo que não se fale pelos Kiriri e nem deles, mas apresentemos as relações de produção da fala e do sujeito como modo de exibir a correlação de forças de produção dos sujeitos, para ampliarmos os leques de possibilidades interpretativas a partir das novas perguntas e dados do campo que viessem proporcionar "transformações de nossas percepções teóricas" (PEIRANO, 2014).

Portanto, este artigo busca trazer à cena uma concepção de aprendizagem, de produção e circulação de conhecimento [e também de educação] mais próxima da experiência cotidiana (GOMES, 2014), (COHN, 2000a, 2000b, 2000c, 2002), (TASSINARI et al., 2017). No caso das famílias Kiriri de Jacobina, a prática da cerâmica e seu aprendizado têm se colocado como central, tanto no sentido de uma "experiência cultural", que requer certas habilidades, educação da atenção 4 (INGOLD, 2010) quanto como um marcador de "indianidade" que se coloca "para fora", sobretudo a partir da venda da cerâmica. Concordamos com Coelho e Debortoli (2012, p. 132) quando afirmam que "aprendemos porque participamos e compartilhamos a vida, relacionando-nos como seres, humanos e não humanos, com os artefatos, com as coisas, compartilhando centralidade, relações e formas de participação".

\section{OS INDÍGENAS KIRIRI: BREVES CONSIDERAÇÕES HISTÓRICAS}

Semelhante à maioria dos povos indígenas no Nordeste, a longa história de contato dos Kiriri foi marcada por profundas intervenções e transformações socioculturais que, no início do projeto colonizador europeu, teve na ação missionária um importante instrumento de coerção, caracterizado por uma prática pedagógica colonizadora, pautada na subalternização e tutela indígena. A recuperação da própria história é um dos aspectos mais significativos no movimento deflagrado pelo povo Kiriri para a retomada das terras do antigo aldeamento de Sacos dos Morcegos, criado em 1700, o qual, após a expulsão dos jesuítas em 1756, foi elevado à condição de

\footnotetext{
4 “É através de um processo de habilitação (enskilment), não de enculturação, que cada geração alcança e ultrapassa a sabedoria de suas predecessoras. Isto me leva a concluir que, no crescimento do conhecimento humano, a contribuição que cada geração dá à seguinte não é um suprimento acumulado de representações, mas uma educação da atenção" (INGOLD, 2010, p. 7).
} 
vila, em 1760, adotando o nome de Mirandela, uma referência à vila de mesmo nome da região Norte de Portugal (BRASILEIRO, 1996; GUIMARÃES, 2014).

Segundo dados do IBGE (2012), a população na Terra Indígena Kiriri -TI Kiriri é de 3.079 indivíduos, aos quais se somam os Kiriri que vivem na TI Kiriri de Barra, localizada no município de Muquém do São Francisco, à margem esquerda do médio rio São Francisco, com 62 ha e uma população de 157 pessoas que, em 1988, passou a abrigar um grupo liderado pela cacique Maria Kiriri, egresso da TI Kiriri, localizada no município de Banzaê/BA. Além desse grupo, há outro que vive no município de Barreiras, com 27 indivíduos, que reivindicam a área denominada Posto Agropecuário de Barreiras, com 126 ha, que foi repassada à Fundação Nacional do Índio - FUNAI em 2007, mas indevidamente utilizada para assentamentos de não índios pela Companhia de Desenvolvimento dos Vales do São Francisco e do Parnaíba - CODEVASF, em 2010 (CEDEFS, 2012). Esse grupo é liderado pelo cacique Carlito, também egresso da TI Kiriri (GUIMARÃES, 2014).

Segundo Guimarães (2014), apesar do movimento de emergência étnica dos índios do Nordeste ter-se iniciado no final da década de 1920, o seu reconhecimento efetivo, enquanto objeto de interesse acadêmico, só se efetivará a partir da década de 1970, praticamente 50 anos depois, através dos estudos antropológicos pioneiros realizados por Bandeira (1972), e, logo depois, por Agostinho (1974, 1978a, 1978b), Carvalho (1977a, 1977b, 1982a, 1982b, 1984, 1994, 2011), Reesink, (1983, 1984), dentre outros. Na década de 1990, esse processo se consolidará com as pesquisas realizadas por Barreto Filho (1992), Oliveira (1994, 1999), Brasileiro (1996), Arruti (1996), Souza (1996) Nascimento (1994), entre outros, que passaram a destacar aspectos como a reorganização política e afirmação das identidades étnicas desses povos, que ainda eram dados como extintos ou vistos na condição de "assimilados".

Esse novo olhar sobre a questão indígena no Nordeste só foi possível graças à recorrência dos pesquisadores a novos aportes teóricos, de modo especial os estabelecidos por Barth (1976), ao atribuir ao conceito de grupo étnico um significado descolado de uma condição estritamente cultural, reconhecendo sua condição relacional, emergente de um contexto histórico específico, caracterizado pela interação entre diferentes grupos sociais, o que veio a reatualizar os estudos nessa área. Ao deslocar o seu interesse analítico para a questão da agência dos próprios grupos étnicos, Barth passou a considerar como esses grupos criam e estabelecem a persistência de suas interfaces e fronteiras étnicas, destacando o papel decisivo das relações com outros grupos como elemento modelador de oposições e classificações configuradoras das diferenças (OLIVEIRA, 1994, 1999; ARRUTI, 1996; GUIMARÃES, 2014). 
Já é consenso entre os estudiosos que a ocupação e a história das regiões do baixo médio e do baixo São Francisco, assim como das suas áreas vizinhas, estão intimamente relacionadas com a história da expansão da pecuária no Nordeste brasileiro, visto que são nestes contextos geográficos que se localizavam alguns dos principais centros difusores de tal ciclo pastoril (BANDEIRA, 1972; CARVALHO, 1977a, 1977b, 1994; NASCIMENTO, 1994, 1998; DANTAS, SAMPAIO \& CARVALHO, 1992; BRASILEIRO, 1996; MACEDO DE SÁ, 2009, 2013). A expansão das frentes pecuárias para o interior do Nordeste brasileiro e, da mesma forma a expansão das ações missionárias, vão desorganizando os modos de vida dos diversos grupos étnicos que habitavam esses territórios e, em nosso caso específico, o estado da Bahia.

[...] Reconhece-se, porém, sem dificuldade, a predominância da família Kariri, presente desde o Ceará e a Paraíba até a porção setentrional do sertão baiano, mas não se definem bem os seus contornos já que apenas quatro línguas - Kipeá, Dzubukuá, Kamuru e Sapuyá - chegaram a ser identificadas e apenas primeira delas suficientemente bem descrita. [...] Os DzubukuáKariri, habitantes da metade ocidental do arco formado pelo submédio São Francisco, contam com os importantes relatos missionários dos capuchinhos Martinho e Bernardo de Nantes (respectivamente, 1707 e 1709). A leste destes e até a altura da cachoeira de Paulo Afonso, o vale do rio era dominado pelos Proká e Pankararu, enquanto a oeste, nas proximidades das atuais cidades de Juazeiro e Petrolina e da desembocadura do rio Salitre, as fontes apenas referem a presença dos Okren, Sakrakrinha, TaniiUikin, Koripó, Masakará e Pimenteiras, estes últimos os mesmos que seriam batidos nos sertões do Piauí em época posterior. No sertão ao sul do São Francisco dominavam os grupos kariri (kiriri) e os Payaya, muitos deles conduzidos nos séculos XVII e XVIII para aldeamentos no Paraguaçu, no Jaguaripe e no litoral de Camamu, a fim de defender o recôncavo da Bahia de Todos os Santos do avanço dos "Aimoré". No sertão ao norte do São Francisco a diversidade de designações étnicas é ainda maior. O planalto da Borborema, a serra dos Kariris e do Araripe e os vales próximos dos rios Jaguaribe, Apodi e Açu registram a presença, junto aos Kariri, dos Iko, Payuku, Kanindé, Otxukayana (Janduí, Tarariu), Inhamun, Calabaça, Xukuru, etc., de cuja pertinência à família Kariri muito se especulou (Pinto, 1938). [...] Nas vertentes do Ibiapaba dominado pelo grupo tupi dos Tobajara, vamos encontrar referências aos Karatiú, Reriú e Anacé, entre outros, enquanto o litoral norte cearense era dominado pelo numeroso povo Tremembé e o baixo curso do Parnaíba pelos Arayó, Anapuru e Aranhi. Finalmente, no árido sertão central de Pernambuco, vale referir a presença dos Xokó e Karapotó, que vamos reencontrar no baixo São Francisco, completando um quadro que não se pretende, de modo algum, exaustivo (DANTAS, SAMPAIO, CARVALHO, 1992, p. 432-433).

É nesse contexto de expansão, representado tanto pela força do Estado Português quanto da Igreja Católica, que os índios Kiriri serão aldeados, por volta da metade do século XVII, na antiga Missão Saco dos Morcegos, constituindo umas das quatro aldeias Kipeá-Kiriri, fundadas pelos jesuítas. Como afirma Nascimento,

O aldeamento desses povos, desde o princípio, se deu em um contexto de conflito com a expansão de frentes pioneiras de criação de gado, que tinham no território 
que margeia o grande rio uma pastagem natural apropriada para o criatório extensivo. Assim, os interesses das ordens religiosas sempre estiveram em conflito com os dos grandes criadores de gado, que não hesitavam em destruir missões, expulsar os padres e massacrar ou escravizar índios. A sobrevivência de algumas destas missões, como a de Saco dos Morcegos, no caminho que liga o recôncavo baiano e a cidade de Salvador ao rio São Francisco, deveu-se ao fato delas constituírem pontos de apoio para a rota do gado, circulação de mercadorias e viajantes, servindo como estalagens. Os índios aldeados prestavam-se, desse modo, à proteção dessas rotas contra os índios brabos, isto é, índios arredios ao contato que se refugiavam nas caatingas e atacavam os viajantes e o gado (1998, p. 69).

Em 1700, diante do acirramento dos conflitos entre os missionários jesuítas e as frentes colonizadoras, o rei de Portugal, através de um alvará, "mandou que se desse às aldeias indígenas uma légua de terra em quadra para sua sustentação. O rei confirmou essa doação em 1703" (LACREVAZ, 2000, p. 27). Na segunda metade do século XVIII, período de expulsão dos jesuítas do Brasil, a área indígena Kiriri, que compreendia os limites da antiga missão, passa a ser expropriada pelos senhores de terra e gado, representados, sobretudo, pela Casa da Torre. Nesse mesmo século, como forma de apagamento da história dos Kiriri na região, a administração colonial modifica o nome da localidade, que de Saco dos Morcegos passa a se chamar Mirandela, sendo elevada, portanto, à categoria de vila (CORTÊS \& MOTTA, 2000).

Na segunda metade do século XIX, é integrada ao território de Ribeira do Pombal, quando da criação deste município, por volta de 1860. O início do século XX inaugura um novo período na história das políticas voltadas para as populações indígenas do Brasil, intimamente ligado à modernização e consolidação do Estado Nacional, com a criação do Serviço de Proteção ao Índio SPI em 1910. Após a instalação do Posto Indígena junto ao povo Kiriri, a atuação do SPI se limitou ao atendimento de pequenas demandas, como a intermediação de conflitos pontuais entre índios e não índios, a realização de um trabalho de assistência agrícola, com a distribuição de sementes e ferramentas, a instalação de uma enfermaria, para atender a necessidades básicas de saúde e, por fim, a instalação de uma escola em Mirandela, que, por ter um quadro reduzido de funcionários (um encarregado e uma professora) e ficar distante das seis comunidades Kiriri localizadas ao longo da área do antigo aldeamento, teve uma ação muito limitada (GUIMARÃES, 2014; BRASILEIRO, 1996).

Como consequência da criação de um Posto Indígena em Mirandela, instaura-se um contexto interétnico mais bem definido, legitimando formalmente a condição indígena dos Kiriri e instituindo um anteparo legal entre esses e a sociedade nacional mais ampla. O acirramento da tensão interétnica conduz o movimento indígena a orientar-se abertamente para a conquista da terra. Nos 20 anos subsequentes à sua instalação, que coincidiram com uma fase de decadência geral do SPI, 
a atuação dos encarregados do Posto notabilizar-se-ia, principalmente, pela intermediação de conflitos isolados entre os índios e os não-índios ocupantes de suas terras e pelo atendimento de algumas de suas pequenas demandas, tais como construção de escolas, posto de saúde, doação de ferramentas, remédios etc. (BRASILEIRO, 1996; SANTANA, 2007). Conforme Nascimento,

No início dos anos sessenta, quando passam a contar com o auxílio de organizações não-governamentais como o CIMI e a ANAÍ-BA, bem como do próprio movimento indígena nacional, os índios Kiriri divisaram a possibilidade de se reorganizarem etnicamente, revertendo o processo de desarticulação política de sua população que, até então, encontrava-se à mercê das imposições dos fazendeiros e políticos locais. Sua organização política foi concomitante à retomada de suas tradições culturais, através do reaprendizado do ritual do Toré, que os Kiriri foram buscar junto aos índios Tuxá (Rodelas- BA), considerados por eles como parentes de outra rama. (NASCIMENTO, 1998, p. 69).

A revitalização ou adoção de rituais, um fato recorrente, nas últimas décadas, entre os povos indígenas do Nordeste, deve ser pensado à luz do seu papel fundamental de mediação entre o passado e o presente, viabilizando a aproximação de valores tidos como tradicionais e assim assegurando um direito legítimo e histórico de reconhecimento à condição indígena e as garantias que daí advém (BRASILEIRO, 2007). "A sua relevância entre os índios do Nordeste extrapola o campo estritamente religioso, ramificando-se em outras esferas, notadamente a política, que, em certas situações sociais, assume preponderância sobre o elemento religioso" (BRASILEIRO, 2007, p. 209).

Na medida em que o ritual do Toré se torna o mais importante suporte ideológico Kiriri na construção de sua etnicidade, e tendo em vista que a reorganização interna desse povo vai sendo construída num esforço de composição política entre as diversas chefias daquelas parentelas que habitavam os diversos núcleos que compunham a área Kiriri (naquele momento ainda não demarcado) (NASCIMENTO, 1994), a disputa pelo controle do ritual constitui fator importante para o desencadeamento de um processo que culminaria, em fins da década de 1980 e início de 90, em uma divisão seccionalista ${ }^{5}$ entre os Kiriri, que permanece até o presente momento (BRASILEIRO, 1996).

Diante de todo o contexto histórico e social de retomada étnica dos Kiriri podemos compreender o caráter multidimensional da etnicidade que compõe os processos de distintividade nas relações étnicas internas e externas. O acervo irredutível do qual os Kiriri se instrumentalizaram para afirmar suas identidades diferenciadas a partir de uma unidade étnica frente ao estado e aos

\footnotetext{
${ }^{5}$ Conforme Nascimento, após a divisão seccionalista, "é através ainda do ritual que se tenta sustentar isso no âmbito de cada uma delas, como prova a reduplicação em ambas da mesma estrutura de poder" (NASCIMENTO, 1994, p. 261).
} 
brancos, são os mesmos diacríticos articulados para demarcação e indicação das distinções internas. A reestruturação da organização política a partir de caciques, conselheiros e pajés, suas práticas culturais com a ciência do índio e os rituais ancestrais, a reorganização da vida social da comunidade pelas ideias coletivistas, entre outros elementos diacríticos de distintividade étnica vão compor um "regime indígena" (CARVALHO, 1994).

Nesse sentido, a história da família Kiriri localizada em Jacobina é uma continuidade da história dos Kiriri de Mirandela supracitada e apontada nas etnografias realizadas sobre esse povo. Conforme Brasileiro (1996), os processos de desorganização das aldeias e de ocupação progressiva das terras mais produtivas do território indígena Kiriri por posseiros e fazendeiros restringiu drasticamente o espaço disponível voltado à produção econômica desse povo, na medida em que foram repelidos para áreas remotas e de inferioridade quanto à qualidade do solo. Os Kiriri se constituíram economicamente a partir de atividades de subsistência: com produções agrícolas aquém das suas necessidades de consumo, comercialização da produção excedente da roça, frutos e de artesanatos em trançados e cerâmica nas feiras de cidades próxima, além de trabalhos para fazendeiros.

O contexto de escassez de recursos naturais, a exploração por parte dos posseiros e o consumo de álcool piorava ainda mais a situação desta família e de muitas outras, tanto em relação ao pagamento dos trabalhos dos índios em troca de cachaça, quanto aos efeitos do consumo de álcool nas relações familiares e sociais dos Kiriri. Tais dificuldades de sobrevivência levaram está e muitas outras famílias a saírem da aldeia e realizarem migrações temporárias para trabalharem e/ou migrações definitivas para outras regiões antes do período de lutas pelas retomadas das terras (BRASILEIRO,1996)

Os conflitos e tensões nas relações por eles empreendidas são evidentes, nas quais podemos perceber o protagonismo destes sujeitos. Os embates com os brancos, as fugas para o mato por conhecerem o território, a criação de roças comunitárias nos limites da terra indígena para pressionar as diversas posses de regionais ali situadas, o fechamento de estradas importantes para o trânsito de regionais e consequentemente retirada de suas posses, a reorganização das tradições e das lideranças políticas, dentre outras estratégias que foram usadas pelos Kiriri para conseguirem retomar seu território. 


\section{REGIME DE CONHECIMENTO E A PRODUÇÃO DE CERÂMICA KIRIRI EM JACOBINA/BA}

Retirantes das suas terras, na década de 1960, por conta das dificuldades para sobreviver após a redução de matas nativas, das caças e pescas com a aproximação das populações regionais dos que atualmente são os municípios de Banzaê, Quijingue e Ribeira do Pombal, uma família Kiriri percorreu alguns municípios e fazendas até chegar em Jacobina/BA e se estabelecer na zona rural do Pontilhão que, segundo essa família, deu-se em decorrência da proximidade com minas de barro voltadas à fabricação de cerâmica e pela facilitação que lhe foi dada pelo dono das terras onde essas minas se localizavam. Atualmente, são 12 famílias que em sua grande maioria vivem da produção de cerâmicas e de tijolos de barro.

A justificativa da saída de sua família da aldeia foi a busca por condições melhores de vida. As promessas de fartura e de qualidade de vida realizadas pelo irmão mais velho que já tinha ido embora da aldeia como também a condição de que os irmãos ficassem juntos para se cuidarem fizeram com que toda a família deixasse Mirandela. Entretanto, a vida no mundo dos brancos foi ainda mais difícil por terem que se adaptar em regiões desconhecidas e longe da aldeia, fazendo com que a família transitasse por diferentes cidades e patrões. O sustento da família continuou sendo o trabalho nas roças, com o manejo do barro em olarias de brancos; contudo, o descontentamento com os resultados do trabalho assalariado e o desejo de autonomia fez com que a família se mudasse para Jacobina. Os conhecimentos sobre o barro possibilitaram ao Sr. Luís e a Sra. Isabel voltar a trabalhar para si mesmo com as produções de cerâmicas, comprar um pedaço de terra, construir sua casa e juntar toda a família.

Em Jacobina/BA, as condições geográficas da região, a proximidade ao rio e à lagoa Antônio Sobrinho, com acesso sem custos ao barro e as condições de pagamento das terras favoreceram para permanência do pequeno núcleo familiar e viabilizou seu sustento a partir das práticas de produção e comercialização de cerâmicas e tijolos. Nesta cidade, os Kiriri se compreendem como um coletivo composto por índios legítimos, índios misturados e não índios, uma vez que os índios que saíram da aldeia de Mirandela são considerados "puros"; os seus descendentes se apresentam como misturados, por serem fruto de casamentos interétnicos. No entanto, quando pergunto a $D$. Odenete se seus filhos eram Kiriri a resposta que recebo é que eles eram na aldeia e que ali em Jacobina não. Nesses termos, ser mais ou menos Kiriri passa pela relação que se estabelece com o território e com os parentes que lá permaneceram. Existem, portanto, níveis/gradientes que marcam essa condição de indianidade, que não é exclusivo dos Kiriri, posto que se apresentam em 
outros contextos, como demonstraram Santana (2015) e Rocha (2014) entre os Tupinambá de Olivença.

Edileuza mobiliza, ademais, outro fator de diferenciação ou de produção de uma "identidade indígena" situacional que passa pelo reconhecimento e garantia de direitos, de modo que para ela só são reconhecidos índios pelo Estado aqueles que permanecem na aldeia, no território Kiriri, "onde o governo garante os direitos dos índios", o que não ocorre em relação às instituições municipais de Jacobina; por isso, nesta cidade, eles não são tratados como indígenas no que tange à garantia de políticas públicas específicas para as comunidades indígenas. No entanto, contraditoriamente, o reconhecimento de uma identidade indígena é mobilizado quando essas famílias são convidadas, por representantes do poder público e membros de instituições de ensino de Jacobina, a fazerem falas sobre os índios, a exemplo do dia do índio, e expor suas peças de cerâmica como representação da "cultura indígena" e, nesse sentido, os Kiriri mobilizam a sua cultura, com aspas, como formulou Carneiro da Cunha (2009a). Nesse sentido,

[...] falar sobre a "invenção da cultura" não é falar sobre a cultura, e sim sobre "cultura", o metadiscurso reflexivo sobre a cultura. [...] a coexistência de "cultura" (como recurso e como arma para afirmar identidade, dignidade e poder diante de Estados nacionais ou da comunidade internacional) e cultura (aquela "rede invisível na qual estamos suspensos") gera efeitos específicos (CARNEIRO DA CUNHA, 2009a, p. 373).

As cerâmicas, símbolos de indianidade deste grupo familiar, são agenciadas como elementos culturais, "sinais diacríticos" (CARNEIRO DA CUNHA, 2009b) que marcam a relação dos Kiriri com os não indígenas da cidade. Por serem considerados "índios do Pontilhão", muitas escolas, no dia do índio, os convidam para falarem sobre sua condição de indígenas; ademais, as escolas costumam levar seus alunos à comunidade para acompanharem o processo de produção da cerâmica. A singularidade das peças de cerâmica de Edivânia atualizam modos de conhecer/aprender próprio dos Kiriri e não é à toa que ela e os demais Kiriri são convidados a falar sobre a história de sua família e de suas relações com os Kiriri de Mirandela. Durante a entrevista Edivânia falou sobre as visitas que recebem das escolas:

Tem gente que procura, em Jacobina a gente é bastante reconhecido, eles vêm de lá para cá. E como é estrada também, os que passam e vê, já param, aí é assim. [...] Aqui os pessoal chama a gente para participar de eventos, e o que participa da organização ou liga, ou vem aqui. Aí convida a gente. Quando a gente não tem condição de lavar o nosso produto, eles leva, não cobra nada, traz. [...)] O pessoal sempre vem aqui. No dia do índio o pessoal vem. Tem vez que chega os pessoal das escolas, que primeiro eles, tem uns não, que chegam em cima da hora, assim, a gente num tem nem como nem tá coisando, porque o certo é falar né, primeiro, organizar isso, é assim, como não é. Aí...tem algumas escolas que já sabe e 
praticamente quase todo ano vem. Um tempo desse num foi nem no dia do índio, veio uma escola aqui, veio dois ônibus, acho que era dois turnos diferentes, num sei, ou era a quantidade de aluno que era demais. Aí vieram. Até carregaram, nesse dia também eu ia enfornar, queimar um forno. Aí minhas peças tá lá na frente, e eu queimei nesse forno aí (apontando para um forno no final do quintal). "Ah posso ajudar": os meninos tudo coisado, curioso assim, "Aah posso ajudar". Eu falei assim: Óh, num quebrando. Aí cada um pegou uma peça, só sei que graças a Deus carregaram tudo. (Entrevista realizada dia 9 de janeiro de 2018).

A produção da cerâmica Kiriri e de tijolos é o elemento central do sustento deste grupo familiar, complementado pela produção agrícola, pesca e trabalhos avulsos. Inicialmente, as peças eram comercializadas na feira livre desde a chegada dos primeiros Kiriri a Jacobina. Atualmente, no entanto, por dificuldades de locomoção, as peças passaram a ser comercializada apenas em frente à casa e em eventos de exposição, quando convidados e custeados. As necessidades e desejos desta família se desenvolvem no conhecimento comunitário da prática de fazer cerâmica; os homens, da primeira e segunda geração, preparam o barro, fazem tijolos, manilhas e ajudam nos momentos de raspagem das peças, mas a produção da cerâmica é realizada majoritariamente pelas mulheres. Romário, filho de Edileuza, que faz parte da terceira geração, é o único que realiza todos os processos de produção das peças de cerâmica.

Esta dinâmica de sociabilidade presente na produção e comercialização das peças de cerâmica também constitui a organização espacial do terreno onde moram. Atrás das quatro casas que ficam na rua principal do Pontilhão existe um grande quintal compartilhado. Nele, existem plantações, fornos de queima das peças de cerâmicas e tijolos, galinheiro, restos de peças quebradas, barracão, barro, cachorros, crianças brincando, árvores e outras casas.

A organização social desta família é toda afetada por esta prática do povo Kiriri, posto que os conhecimentos dos seus antepassados ainda fundamentam seus saberes e fazeres em torno da produção da cerâmica que se configura em espaço de aprendizagem e afirmação da identidade Kiriri, de modo que a experiência empírica é compartilhada na garantia da manutenção de um modo de vida especifico (LUCIANO, 2006). São nas atividades cotidianas que as crianças vão elaborando e recriando a cultura. Romário e Edivânia aprenderam com seus mais velhos a fazer as peças de cerâmica e a vender na feira juntos com peças de sua mãe e avó. Daniela, Geilson e Marcos estão aprendendo com seus pais e avó a fazerem as peças; por outro lado, quando não fazem, acompanham seus pais nas vendas, nas buscas por lenha e indo armar a rede para pescar nos períodos de cheia da lagoa, aprendizados considerados importantes pelos Kiriri. 
Bandeira (1972), em pesquisa pioneira junto aos Kiriri, apresenta-nos características da educação desse povo no que concerne a aspectos como a responsabilidade dos pais e/ou mestres em relação ao ensino das artes às crianças, ressaltando que caso os pais não dominassem a técnica de certos ofícios, seus filhos poderiam aprender com mestres e tias. No entanto, como salienta Bandeira (1972), o aprendizado da cerâmica (potes em diversos tamanhos, porrões, aribés, panelas, frigideiras, cuscuzeiros) é uma especialização feminina, que passa de mãe para filha. Quando as exceções ocorriam, constituía-se uma relação analógica à adoção.

O caráter multidimensional da etnicidade que abarca o contexto histórico e social do povo Kiriri também é evidenciado no interior do grupo familiar Kiriri de Jacobina e na sua relação com a comunidade externa. Os elementos diacríticos por eles acionados para definição da sua distintividade étnica estão em constante negociação no processo de definições endógenas e exógenas para o reconhecimento de sua indianidade, de modo que a questão biológica aparece de forma contraditória em alguns dos relatos coletados na pesquisa, uma vez que em alguns momentos o parentesco e o sangue são acionados como diferenciador do ser Kiriri e/ou de ser Kiriri "mais verdadeiro" em relação aos misturados. A associação entre o sangue e a cerâmica nos demonstra a instrumentalização de um irredutível acervo diacrítico em níveis de distintividade étnica que são por eles agenciados na composição de suas identidades étnicas.

Para os que os veem de longe, eles são uma família de indígenas do Pontilhão de Jacobina (Edivânia, 2018), quando nos aproximamos são famílias com indígenas que vivem no Pontilhão (Edivânia, 2018) e quando suas identidades são questionadas ao associar a produção da cerâmica do grupo familiar como sendo algo de índio, eles respondem que todos são aprendizes Kiriri (Edileuza, 2017) e que mantêm a tradição da cultura Kiriri (Romário, 2019). Roberto Cardoso de Oliveira (1976) assinala o emaranhado de sentidos instituindo a produção das identidades étnicas pelas identificações e a manipulação das identidades, reconhecendo-as por meio das interpretações dos agentes em interação nos sistemas interétnicos. A imprevisibilidade de escolha dos traços culturais pelos grupos étnicos na produção de suas fronteiras não é arbitrária, como também a identidade étnica em suas dinâmicas e modulações.

Para Barth (1976), as fronteiras étnicas são o jogo sendo jogado pelos sujeitos que compõem um grupo étnico, por meio da qual uma estrutura de interação permite a persistência de diferenças culturais, uma relação de oposição entre um outro e um nós. Nessa medida, a pertença étnica se alimenta de características diferenciadoras e organizacionais de estilo de vida distintivo, determinando um tipo particular de grau social, no qual um sistema de divisões sociais vai se 
constituir por meio da validação de honra e de prestígio dos sujeitos inseridos nos grupos étnicos. Perfila-se, portanto, que a pertença étnica enquanto crença subjetiva na comunidade de origem e/ou ancestralidade comum são um dos múltiplos fatores que atuam na produção da etnicidade, do qual insurgem os agenciamentos de elementos culturais diacríticos, organizadores sociais do grupo, com um efeito diferenciador e fronteiriço. Observando estas pontuações, podemos afirmar que a noção de indianidade está muito ligada a continuidade histórica das práticas indígenas, que mesmo com a incorporação da população negra às relações de parentesco, pelos casamentos, não teria implicado na quebra dos fundamentos do sistema de crenças do grupo; pelo contrário, os que chegaram tiveram que aprender e a viver na/da produção de cerâmica, de modo que a oposição interna se dilui na afirmação do nós, do grupo familiar, diante dos outros, a sociedade jacobinense.

Nesse sentido, o foco desta pesquisa "incide sobre a continuidade interindígena visível apesar das diferenças de conteúdo derivadas das diferentes situações de contato envolvidas" (VIVEIROS DE CASTRO, 1999, p. 149). Reesink (2007) apresenta como a questão de sangue, parentesco e etnicidade estiveram presentes no debate em torno dos grupos indígenas do Nordeste, desempenhando diferentes noções e funções diante da complexidade histórica estabelecida pelos longos anos de convívio com os não-índios demonstrando que, na maioria dos contextos, os casamentos interétnicos se deu entre negros e índios e que as semelhanças culturais assim como a ênfase na manutenção dos aspectos culturais diferenciados se sobrepunham às questões sanguíneas na legitimação étnica destes povos.

Ademais, Chates (2011) salienta que não visualiza entre os Kiriri de Mirandela que a regra de proibição de casamento interétnico fixada após o processo de reafirmação étnica e de demarcação das terras dos Kiriri constitua uma construção biologizante de família ou do parentesco, por identificar que para muitos Kiriri ter a consanguinidade não é garantia de reconhecimento de ser parente da mesma etnia.

Macêdo de Sá (2009) afirma que existem expressivas singularidades sócio-culturais reelaboradas e resignificadas pelos Kiriri, de modo que, segundo a autora, se constrói e se realiza a experiência cultural da aprendizagem e os aprendizados que estruturam a sua cultura, através das narrativas e das experiências vivenciadas por esse coletivo. A experiência em si revela o próprio processo de aprendizagem se realizando, de forma que o aprendizado é uma experiência cultural. Conhecer é experimentar e, nesse sentido, a cultura é um modo de operar relações e, nesse sentido, precisa ser ensinada, aprendida, experienciada, vivenciada, aspecto que tem sido observado em outros contextos ameríndios, como apresentam Santana (2015), em sua etnografia sobre os 
Tupinambá de Olivença/BA, e Oliveira (2012) em relação aos Wajãpi, grupo de língua Tupi-Guarani localizados no Amapá.

Ademais, conforme Macedo Sá (3013), ouvindo e aprendendo sobre os encantos, as qualidades dos animais, as hierarquias xamanísticas, os Kiriri fazem a manutenção dos seus símbolos culturais, reforçam seu lugar no mundo ocidental, valorizam suas crenças e identidades grupais, se afirmam e se reconhecem enquanto índios na sua especificidade étnico-cultural. "A aprendizagem, enquanto experiência seria, então, processo de mediação entre o sujeito e a sociedade e vice-versa, ou seja, a experiência em si é o próprio processo de aprendizagem inserido no contexto de diversos símbolos compartilhados que constituem a cultura" (2013, p. 98).

Dentre os trabalhos em que a produção de cerâmica é discutida, encontra-se a pesquisa de Bandeira (1972) na qual a autora pontua que o artesanato alcançou historicamente um peso significativo na economia deste povo, constituindo-se como um dos fatores de diferenciação discriminatória da cerâmica Kiriri, indicando que:

se considerarmos a validade dos informes sobre atividade cerâmica entre os Kariri (sic) e de que se ocupassem igualmente de trançados e tratamento de fibras, sem nos importarmos que as técnicas fossem ou não originais na cultura tribal, teremos de todo modo, frente à posição dos dois grupos, uma ocupação cabocla. Ora, tendo em vista o preconceito ciosamente transmitido da inferioridade étnica do índio, é ao menos de aguda verossimilhança que tais atividades permanecessem próprias de caboclo. As portuguesas consideram cerâmica, trançados, tratamento e fiação de certas fibras como coisas de caboclas, ocupação indigna de sua posição social (BANDEIRA, 1972, p. 59).

Brasileiro (1996) pontua a existência da produção de cerâmica entre os Kiriri e sua comercialização por alguns núcleos familiares no decorrer do processo de reorganização étnica e luta pela terra, nas últimas décadas do século XX. Segundo a autora (1996, p. 67), "ao mercado também se destina, com certa periodicidade, o produto da coleta de frutos silvestres, como cajú, umbú e pinha, além de, mais esporadicamente, um artesanato trabalhado em cerâmica e trançados. Macêdo de Sá (2013) também apresentas relatos de uma entrevista com a jovem Yamke Kiriri em que pergunta qual é a coisa mais importante que ele aprendeu na vida e com quem, cuja resposta foi a descrição do processo de produção de cerâmica.

O barro é encontrado na aldeia perto de Mirandela. Os artesãos vão em grupo com amigos e família, com animais ou trazem na cabeça num saco. Para cavar o barro, os mesmos levam cavadeira ou chibanca porque o barro é duro. Quando chegam em suas casas, o barro é amassado com uma pedra. Depois de amassado, colocam água e deixam de molho durante a noite. No dia seguinte, o artesão amassa mais uma vez para fazer potes, panelas, arribés, moringas, pratos, tijelas, etc. Depois de feitos, durante o dia, os objetos são observados para alguns consertos. Depois de secos, os objetos são raspados para serem pintados com o tauá amarelo ou não. 0 
artesão deixa secar a tinta e alisa com uma semente conhecida como mucunã. Depois de alisados, os objetos são novamente pintados; desta vez, são os detalhes com o tauá vermelho, amarelo, preto e outros. Depois de tudo pronto, os artesãos vão buscar lenha para ser colocada no forno para queimar os objetos. O forno é construído com barro, tijolo e cipó do mato, por duas ou mais pessoas da aldeia que tiveram a possibilidade de aprender com um artesão mais velho como Vital Luiz de Sousa (MACEDO DE SÁ, 2013, p. 92).

Chates (2011) apresenta, de forma minuciosa, as cartilhas produzidas pelo "Projeto Kiriri" realizado pela Associação Nacional de Ação Indigenista - ANAÍ em 1983, especificamente a cartilha que trata sobre a produção da cerâmica. Como afirma a autora,

No contexto de articulação entre a sações de cada subprojeto do "Projeto Kiriri", ou seja, o de educação, o de saúde e o das roças comunitárias, foram produzidas cartilhas. Entre elas, uma que tinha o intuito de oferecer informações para que os índios tivessem uma vida mais saudável, com base em elementos da medicina tradicional Kiriri- a "medicina do mato" -e a medicina dita ocidental. Em tal cartilha, além de informações referentes tanto à medicina Kiriri e à medicina não indígena, eram apresenta das algumas práticas alternativas, como exemplo, escovar os dentes sem utilizar pasta e escova de dentes. (...) Nesta ocasião, foi realizado um levantamento de ervas medicinais, e também o incentivo às práticas comunitárias tradicionais Kiriri e a o artesanato. O levantamento não somente tratou das plantas para fins medicinais, mas verificou-se uma maior degradação do Território Kiriri. A taboca, para confecção da gaita, assim como o caroá, para tecer redes, e o barro eram difíceis de encontrar, como relata Côrtes (1996). Um levantamento do artesanato Kiriri também foi realizado, como objetivo não somente de catalogar, mas sistematizaras técnicas artesanais. Nessa perspectiva, foi escrito um material intitulado "A cerâmica Kiriri", por Patrícia Kafure. (...) Além da cartilha de saúde e do levantamento da cerâmica Kiriri, foi montada pelos monitores, a partir dos círculos de cultura como os estudantes, a "Cartilha da Escola Kiriri: Português, livro1Alfabetização". As palavras geradoras foram usadas como recurso, de acordo como Método Paulo Freire. Entre as palavras geradoras presentes na cartilha, a primeira é "pote", destacada por Côrtes (1996, p. 89) como símbolo de afirmação étnica Kiriri. Ou seja, a aquisição da escrita, nesse exemplo, esteve relacionada à afirmação de elementos diacríticos da etnicidade Kiriri, pois, o objeto citado não identifica o povo Kiriri somente diante de si, mas também diante dos regionais, através do reconhecimento da boa qualidade do artesanato Kiriri (CHATES, 2011, p. 100-102).

Nesse sentido, a cerâmica se constituiu a partir de um discurso que vai afirmando a continuidade dos conhecimentos indígenas e da educação indígena Kiriri na fabricação das peças e na produção de identidades diferenciadas com referências aos valores tradicionais indígenas. Os conhecimentos produzidos e transmitidos pela tradição, aprendidos pela experimentação, não se perderam, mesmo diante da investida do Estado brasileiro no sentido de assimilá-los e, portanto, negar as suas dinâmicas socioculturais.

Conforme Edvânia kiriri, o seu processo de aprendizagem se deu pela observação da sua mãe trabalhando e, em seguida, com as mãos da avó pegando as suas e conduzindo o aperto do barro, 
com muita paciência. Os elementos da natureza, barro, sementes, água e fogo são utilizados na composição das peças. A observação, escuta e as criações inventivas constituída de técnicas, processos, esforço, saberes, práticas educativas, desejo de aprender, persistência, traços singulares assim como as imprecisões, quebras, sol e chuva, pinturas e tonalidades variadas nas produções das peças constituem o fazer dos aprendizes. De modo que "cada um tem seu jeito. É muito complicado! Aprendendo pelo desejo de experimentar. Quando as crianças quer brincar com o barro, a gente deixa", como afirmou Edvânia. Desde criança fazem suas peças de forma autônoma, enquanto aprendem as técnicas, saberes e manuseios com o barro, produzindo miaeiros tortos para vender, brincando enquanto aprendem, até irem aperfeiçoando o trabalho no decorrer da vida, de forma a produzir "processos de autossustentação", como afirma Silva (2012), referindo aos Pataxó.

O processo de transmissão e aprendizagem relatado por Edvânia perpassa pelo valor da ação, do aprender fazendo, de forma que a natureza do conhecimento não diz respeito apenas ao conteúdo, mas pela capacidade de agência do sujeito aprendente. Segundo Edvânia, sua avó Isabel reclamava de sua mãe Edileuza, posto que ela tinha pouca paciência em transmitir o conhecimento para a filha; esta impaciência fazia com que a avó conduzisse a neta à experimentação do barro e ao aprendizado da fabricação das peças de cerâmica. Nas memórias da infância com a sua avó, Edvânia e Romário relatam momentos em que ela Ihe transmitia os conhecimentos e os convidada para participar de atividades de plantação, de reza e da feitura da cerâmica.

As narrativas de Edvânia e Romário sobre como aprenderam a fabricar as peças de cerâmica apontam para observação e experimentação como forma de aprender e ensinar, assim como o preferir fazer ao falar, como enfatizou Romário, quando faz referência ao significado do nome da sua etnia, "povo calado" e se disponibiliza em mostrar o passo a passo da produção da peça de cerâmica. Essa concepção de ensino e aprendizagem é bem explorada por Macêdo de Sá (2013), quando afirma que a centralidade da aprendizagem na educação indígena Kiriri está na oralidade, observação, imitação e exemplificação das atividades no cotidiano, aspectos também observados por Cohn (2000a, 2000b) em suas pesquisas junto aos Xikrin da Terra Indígena Bacajá, no estado do Pará.

\section{CONSIDERAÇÕES FINAIS}

A produção antropológica sobre os coletivos ameríndios tem buscado compreender uma diversidade de formas locais sobre a produção e circulação de conhecimentos que, conforme Lima (2011, p. 170), apresentam "a diversidade dos próprios processos de conhecer, feitos de trocas, 
viagens, empréstimos, transformações e inovações". Conforme Luciano (2006), são os processos educativos e os saberes por eles transmitidos que garantem a produção de uma cultura e identidade entre os coletivos ameríndios, que certamente envolve relações de trocas e "traduções interculturais", como afirmam Bona e Luna (2020) e que, de alguma forma, tencionam campo da educação escolar, elaboram novas perspectivas de conhecimento e de currículo que se pretendem emancipadores (SOUZA, 2016), capazes de produzir "inovações curriculares e pedagógicas" (DIAS; MENEZES, 2017; KOVACS; TINOCA, 2017). Não à tão que as práticas de conhecimentos consideradas tradicionais adquirem centralidade na escola.

Ao privilegiarmos a produção da cerâmica pelas famílias Kiriri que habitam a cidade de Jacobina/BA e os processos de aprendizagem que movimentam essa construção, não buscamos por uma gênese ou pureza da arte ceramista e muito menos da etnia. Longe de apresentar um quadro acabado dos processos próprios de aprendizagem e transmissão de conhecimento da educação indígena Kiriri, indicamos, ao contrário, possibilidades de apreender como essas questões se colocam empiricamente. A análise visou demonstrar como esse coletivo projetou sua etnicidade demarcando a cerâmica como "traço diacrítico" do grupo em relação aos demais moradores da localidade onde residem e às relações de continuidade dessa prática ceramista com os Kiriri que permaneceram na Terra Indígena, no município de Banzaê/BA, de modo que são nestas relações e na produção de cerâmica que podem elaborar maneiras singulares de construção da alteridade.

Nesse sentido, as novas articulações que esse grupo familiar tem construído, com representação no Conselho de Promoção da Igualdade Racial da cidade de Jacobina, em que o debate sobre "a cultura" começa a ganhar força, possibilitarão outros desdobramentos e construção de novas relações. No momento, estão se organizando para criação de uma associação de indígenas Kiriri do Pontilhão de Jacobina, tendo Romário como liderança, para começarem a reivindicar seus direitos frente as instituições municipais e aos demais órgão públicos da cidade de Jacobina, bem como para participarem ativamente da produção e execução de projetos que visem a melhoria de suas condições de vida.

\section{REFERÊNCIAS}

AGOSTINHO, Pedro. Identificação étnica dos Pataxó de Barra Velha, Bahia. In: MEMORIAM António Jorge Dias. Lisboa: Instituto de Alta Cultura/Junta de Investigações Científicas do Ultramar, 1974. v.II, p. 393-400. 
AGOSTINHO, Pedro. Bases para o estabelecimento da Reserva Pataxó. Revista de Antropologia, São Paulo, n. 23, p.19-29, 1978a.

AGOSTINHO, Pedro. Condicionamentos ecológicos e interétnicos da localização dos Pataxó de Barra Velha, Bahia. Cultura: o Índio na Bahia, Salvador, Fundação Cultural do Estado da Bahia, ano1, n.1, p. 71-77, 1978b.

ARRUTI, José Maurício Paiva Andion. O Reencantamento do Mundo: Trama histórica e Arranjos Territoriais Pankararu. 219f. Dissertação (Mestrado em Antropologia Social), Programa de PósGraduação em Antropologia Social, Museu Nacional, 1996.

BANDEIRA, Maria de Lourdes. Os Kariris de Mirandela: um grupo indígena integrado. Salvador: UFBA, 1972. (Estudos Baianos, 6).

BARRETO FILHO, Henyo Trindade. Tapebas, Tapebanos e Pernas-de-Pau: etnogênese como processo social e luta simbólica. Dissertação (Mestrado em Antropologia Social) - PGAS, Museu Nacional/UFRJ, Rio de Janeiro, 1992.

BARTH, Fredrik. Introducción. In: F. Barth (Org.). Los grupos étnicos y sus fronteras. México: Fondo de Cultura Económica, 1976. p. 9-49.

BONA, Juliano; LUNA, José Marcelo Freitas de. Relações interculturais e o trabalho de tradução como cartografia: subjetividade, transparência e poder. Revista Tempos e Espaços em Educação, São Cristóvão- SE, v. 13, n.32, p. 1-15, 2020. Disponível em:

https://seer.ufs.br/index.php/revtee/article/view/13282/10450 Acesso: 29 jul. 2020. DOI:

https://doi.org/10.20952/revtee.v13i32.13282

BRASILEIRO, Sheila. A organização política e o processo faccional no povo indígena Kiriri. $250 f$. Dissertação (Mestrado em Sociologia) - Universidade Federal da Bahia, Salvador, 1996.

BRASILEIRO, Sheila. "O toré é coisa só de índio": mudança religiosa e conflito entre os Kiriri. In: BACELAR, Jeferson; CAROSO, Carlos (Orgs.). Brasil: um país de negros? 2 ed. Rio de Janeiro: Pallas; Salvador, CEAO, 2007.

CARNEIRO DA CUNHA, Manuela. "Cultura" e cultura: conhecimentos tradicionais e direitos intelectuais. In: CARNEIRO DA CUNHA, Manuela. Cultura com aspas e outros ensaios. São Paulo: Cosac Naify, 2009a, p. 311-373.

CARNEIRO DA CUNHA, Manuela. Etnicidade: da cultura residual mas irredutível. In: CARNEIRO DA CUNHA, Manuela. Cultura com aspas e outros ensaios. São Paulo: Cosac Naify, 2009b, p. 235-244.

CARVALHO, Maria Rosário G. de. A identidade dos povos do Nordeste. Anuário Antropológico, Fortaleza, UFC, Rio de Janeiro, Tempo Brasileiro, n.82, p.169-188, 1984.

CARVALHO, Maria Rosário G. de. Los Kariri de Mirandela: un subsegmento rural indígena. América Indígena, México, v.87, n.1, p.113-121, 1977a.

CARVALHO, Maria Rosário G. de. Os Pataxó de Barra Velha: seu subsistema econômico.

Dissertação (Mestrado) - Universidade Federal da Bahia, Salvador, 1977b.

CARVALHO, Maria Rosário G. de. Os povos indígenas no Nordeste: território e identidade étnica. Washington, 1982a.

CARVALHO, Maria Rosário G. de. Parecer sobre a identidade étnica Kapinawá. Salvador, $1982 b$. 
CARVALHO, Maria Rosário G. de. De índios "misturados" a índios "regimados". Comunicação apresentada na 19a Reunião da ABA, Niterói, RJ: 1994.

CARVALHO, Maria Rosário G. de. De índios misturados a índios regimados. In: CARVALHO, Maria Rosário de et al. (org.). Negros no mundo dos índios: Imagens, reflexos, alteridades. Natal, Editora da UFRN, 2011.

CHATES, Taíse de Jesus. A domesticação da escola realizada por indígenas: uma etnografia histórica sobre a educação e a escola Kiriri. 2011, 181f. Dissertação (Mestrado em Antropologia) Programa de Pós-Graduação em Antropologia, Universidade Federal da Bahia, Salvador, 2011.

COELHO, Luciano Silveira; DEBORTOLI, José Alfredo Oliveira. Corporalidade e engajamento: participação e aprendizado de crianças e adultos em contextos indígenas. In: ARROYO, Miguel G.; SILVA, Maurício Roberto (Orgs.). Corpo infância: exercícios tensos de ser criança - por outras pedagogias dos corpos. Petrópolis, RJ: Vozes, 2012.

COHN, Clarice. A criança indígena: a concepção Xikrin de infância e aprendizado. 185 p. 2000. Dissertação (Mestrado em Antropologia) - Programa de Pós-Graduação em Antropologia, Universidade de São Paulo, São Paulo, 2000a.

COHN, Clarice. Crescendo como um Xikrin: uma análise da infância e do desenvolvimento infantil entre os Kayapó-Xikrin do Bacajá. Revista de Antropologia, São Paulo, USP, v. 43, n.2. 2000b. Disponível em: <http://www.scielo.br/scielo.php?script=sci_arttext\&pid=S003477012000000200009>. Acesso em: 15 de ago. de 2017.

COHN, Clarice. Noções sociais de infância e desenvolvimento infantil. Cadernos de Campo, Ano 10, v. 9, p. 13-26, 2000c. Disponível em: <http://www.revistas.usp.br/cadernosdecampo/article/view/53068>. Acesso em: ago. 2017.

COHN, Clarice. A experiência da infância e o aprendizado entre os Xikrin. In: SILVA, Aracy; MACEDO, Ana Vera Lopes da Silva \& NUNES, Ângela (Orgs.). In: Crianças indígenas: ensaios antropológicos. São Paulo: Global, 2002, p. 117-149.

CORTES, Clélia Néri \& MOTA, Erimita. História da reconquista de Mirandela: História a várias vozes. Brasília: UFBA, 2000.

DANTAS, Beatriz G; SAMPAIO, José Augusto Laranjeira; CARVALHO, Maria Rosário G. de. Os povos indígenas no Nordeste Brasileiro: um esboço histórico. In: CARNEIRO DA CUNHA (Org.). História dos Índios no Brasil. São Paulo: Companhia das Letras, 1992.

DIAS, Alfrancio Ferreira; MENEZES, Carlos André Araújo. Que inovação pedagógica e pedagogia queer propõe o currículo escolar? Revista Tempos e Espaço em Educação, São Cristóvão-SE, v.10, n. 23, p. 37-48, 2017. Disponível em: https://seer.ufs.br/index.php/revtee/article/view/7443. Acesso: 07 jul. 2020. DOI: https://doi.org/10.20952/revtee.v10i23.7443

GOMES, Ana Maria. Um (possível) campo de pesquisa: aprender a cultura. In: TOSTA, Sandra Pereira; ROCHA, Gilmar (Orgs.). Diálogos sem fronteira: história, etnografia e educação em culturas ibero-americanas. Belo Horizonte: Autêntica, 2014.

GUIMARÃES, Francisco Alfredo Morais. A gente só conhece certo quando vê de perto: um novo olhar sobre a pesquisa entre os professores Kiriri. 277f. Tese (Doutorado em Estudos Étnicos e 
Africanos) - Programa Multidisciplinar de Pós-Graduação em Estudos Étnicos e Africanos, Universidade Federal da Bahia, 2014.

IBGE - INSTITUTO BRASILEIRO DE GEOGRAFIA E ESTATÍ́STICA. Pesquisa Nacional por Amostra de populações indígenas: Kiriri 2012. Disponível em: https://indigenas.ibge.gov.br/estudos-especiais3/o-brasil-indigena/povos-etnias.html Acesso: 12 out. 2018.

INGOLD, Timothy. Da transmissão de representações à educação da atenção. Educação, Porto Alegre, v. 33, n. 1, p. 6-25, 2010. Disponível em:

https://revistaseletronicas.pucrs.br/ojs/index.php/faced/article/view/6777/4943. Acesso: 8 de mar de 2018.

KOVACS, Helena; TINOCA, Luís. Unfreeze the pedagogies: introduction og a nee innovative measure in Portugal. Revista Tempos e Espaços em Educação, São Cristóvão, SE, v. 10, n. 23, p. 73-86, 2017. Disponível em: https:// https://seer.ufs.br/index.php/revtee/article/view/7446/pdf. Acesso em: 07 jul. 2020. DOI: https://doi.org/10.20952/revtee.v10i23.7446

LACRAVEZ, Jean. Datas na história da Nação Kiriri (1549 - 1995). In: CORTES, Clélia Néri \& MOTA, Erimita. História da reconquista de Mirandela: História a várias vozes. Brasília: UFBA, 2000.

LIMA, Edilene Coffaci. Pelos varadouros do alto juruá: cultura e política, saber e saber-fazer. In: LÉPINE, Claude; HOFBAUER, Andreas; SCHWARCZ, Lilia M. (Orgs.). Manuela Carneiro da Cunha: o lugar da cultura e o papel da antropologia. Rio de Janeiro: Beco do Azougue, 2011, p. 159-172.

LUCIANO, Gersem dos Santos. 0 índio brasileiro: o que você precisa saber sobre os povos indígenas no Brasil de hoje. Brasília: MEC/SECAD; LACED/Museu Nacional, 2006. 233p. (Coleção Educação Para Todos. Série Vias dos Saberes n. 1).

MACEDO DE SÁ, Silvia Michele Lopes. Emergência da etnoaprendizagem no campo antropoeducacional: Uma investigação etnológica sobre a aprendizagem como experiência sociocultural. 175f. Tese (Doutorado em Educação) - Universidade Federal da Bahia, 2013.

MACEDO DE SÁ, Silvia Michele Lopes. Educação por outros olhares: aprendizagem e experiência cultural entre os índios Kiriri do Sertão Baiano. Dissertação. Mestrado em Educação. Programa de Pós-Graduação em Educação, UFBA, Salvador, 2009.

NASCIMENTO, Marco Tromboni de Souza. O tronco da Jurema: ritual e etnicidade entre povos indígenas do Nordeste: o caso Kiriri. 324f. Dissertação (Mestrado em Antropologia) - Universidade Federal da Bahia, Salvador, 1994.

NASCIMENTO, Marco Tromboni de Souza. O povo indígena Kiriri. In: SILVA, A. L. Da \& GRUPIONI, L. D. A temática indígena na escola: novos subsídios para professores de 1 으 e 2 o graus (org.) 2 ed. São Paulo: Global; Brasília; MEC; MARI; UNESCO, 1998.

OLIVEIRA, Camila Silva de. Modos de produção e transmissão de conhecimento: um estudo sobre a produção da cerâmica entre famílias Kiriri, em Jacobina/BA. 130f. Dissertação (Mestrado em Relações Étnicas e Contemporaneidade), Programa de Pós-graduação em Relações Étnicas e Contemporaneidade, Universidade Estadual do Sudoeste da Bahia, 2019.

OLIVEIRA, Joana Cabral de. "Vocês sabem porque vocês viram"! reflexão sobre modos de autoridade do conhecimento. Revista de Antropologia, v. 55, n.1, p. 51-74, 2012. Disponível em: <http://www.revistas.usp.br/ra/article/view/46959/66694>. Acesso em: 06 de jan. 2018. 
OLIVEIRA, João Pacheco de. A viagem de volta: reelaboração cultural e horizonte político dos povos indígenas no Nordeste. In: ATLAS das Terras Indígenas do Brasil./Nordeste. Rio de Janeiro: PETI/: Museu Nacional: UFRJ, 1994.

OLIVEIRA, João Pacheco de. Ensaios em Antropologia Histórica. Rio de Janeiro: Editora UFRJ, 1999.

PEIRANO, Mariza. Etnografia não é método. Horizontes Antropológicos. Porto Alegre, v. 20, n. 42, p. 377-391, jul./dez. 2014. Disponível em:

$<$ http://www.scielo.br/scielo.php?script=sci_arttext\&pid=S0104-

71832014000200015\&lng=en\&nrm=iso>. Accesso: 20 Junho 2018.

REESINK, Edwin B. A Questão do Território dos Kiriri de Mirandela: um levantamento histórico. Salvador, 1983.

REESINK, Edwin B. A Questão do Território dos dos Kaimbé de Massacará: um levantamento histórico. Gente, v.1, n.1, p.127-137, 1984. Disponível em: https://dadospdf.com/queue/aquestao-do-territorio-dos-kaimbe-de-massacara-um-levantamento-historico-em-gente-revista-dodepartamento-de-antropologia-da-ufba_5a4bf431b7d7bcab67fa1465_pdf?queue_id=-1. Acesso em: julho de 2018.

REESINK, Edwin B. Uma questão de sangue. In: BACELAR, Jeferson; CAROSO, Carlos (Orgs.). Brasil: um país de negros? 2 ed. Rio de Janeiro: Pallas; Salvador, CEAO, 2007.

ROCHA, Cinthia C. da. "Bora vê quem pode mais": Uma etnografia sobre o fazer política entre os Tupinambá de Olivença (Ilhéus, Bahia). 303f. Tese (Doutorado em Antropologia Social) - Programa de Pós-Graduação em Antropologia Social, Universidade Federal de Santa Catarina, Santa Catarina, 2014.

SANTANA, José Valdir Jesus de. A produção dos discursos sobre cultura e religião no contexto da educação formal: o que pensar/querem os Kiriri de sua escola? 111f. 2007. Dissertação (Mestrado em Educação) - Universidade Estadual da Bahia, Salvador, 2007.

SANTANA, José Valdir Jesus de. A letra é a mesma, mas a cultura é diferente: a escola dos Tupinambá de Olivença/BA. 240f. 2015.Tese (Doutorado em Antropologia Social). Universidade Federal de São Carlos, São Carlos, 2015.

SILVA, Paulo de Tássio Borges da. Diferença, interculturalidade e autosustentação na educação escolar indígena Pataxó. Revista Tempos e Espaços em Educação, São Cristóvão - SE. v. 5, n.9, p. 99-109, jul./dez. 2012. Disponível em:

https://seer.ufs.br/index.php/revtee/article/view/2270/1941 Acesso: 08 jul. 2018. DOI: https://doi.org/10.20952/revtee.v0i0.2270

SOUZA, Jorge Bruno Sales. Fazendo a diferença: um estudo da etnicidade entre os Kaimbé de Massacará. 164f. Dissertação (Mestrado em Sociologia) - Universidade Federal da Bahia, 1996.

SOUSA, Jesus Maria. Repensar o currículo como emancipador. Revista Tempos e Espaços em Educação, São Cristóvão - SE, v. 9, n. 18, p. 111-120, 2016. Disponível em: https://seer.ufs.br/index.php/revtee/article/view/4969. Acesso: 07 jul. 2020. DOI: https://doi.org/10.20952/revtee.v9i18.4969

TASSINARI, Antonella Maria Imperatriz [et. al]. Educação, infância e diversidade: desafios à Antropologia e às políticas públicas. In: MONTARDO, Deise Lucy O; RUFINO, Márcia Regina C. F. 
(Orgs.). Saberes e ciência plural: diálogos e interculturalidade em Antropologia. Florianópolis, SC: Editora da UFSC, 2017.

VIVEIROS DE CASTRO, Eduardo B. "Etnologia brasileira". In: MICELLI, Sérgio (Org.). O que ler na ciência social brasileira 1970-1995. São Paulo: Sumaré, 1999. p. 109-223.

\section{$\underline{\text { SOBRE OS AUTORES }}$}

\section{José Valdir Jesus de Santana}

Doutorado em Antropologia Social pela Universidade Federal de São Carlos. Professor Titular da Universidade Estadual do Sudoeste da Bahia. Professor do Programa de Pós-Graduação em Relações Étnicas e Contemporaneidade e Programa de Pós-Graduação em Ensino da Universidade Estadual do Sudoeste da Bahia. Coordenador do Grupo de Pesquisa em Etnicidades, Relações Raciais e Educação - CNPQ/UESB.

E-mail: jsantana@uesb.edu.br

ORCID: https://orcid.org/0000-0001-7215-2562

\section{Camila Silva de Oliveira}

Mestrado em Relações Étnicas e Contemporaneidade pelo Programa de Pós-Graduação em Relações Étnicas e Contemporaneidade da Universidade Estadual do Sudoeste da Bahia; professora da rede municipal de Coração de Maria/BA.

E-mail: camila mirandaso@hotmail.com

ORCID: https://orcid.org/0000-0001-9425-7621

\section{Danilo César Souza Pinto}

Doutorado em Antropologia Social pela Universidade Federal de São Carlos. Professor Titular da Universidade Estadual do Sudoeste da Bahia. Professor do Programa de Pós-Graduação em Relações Étnicas e Contemporaneidade da Universidade Estadual do Sudoeste da Bahia.

E-mail: danilosouzap@uesb.edu.br

ORCID: https://orcid.org/0000-0001-8771-4708 